\title{
REFLEXÕES SOBRE A PRÁXIS: AS VIVÊNCIAS NO ESTÁGIO SUPERVISIONADO EM HISTÓRIA
}

\section{REFLECTIONS ON PRAXIS: EXPERIENCES IN SUPERVISED INTERNSHIP IN HISTORY}

\author{
Aristeu Castilhos da Rocha ${ }^{1}$ \\ Maria Catharina Lima Pozzebon ${ }^{2}$
}

\begin{abstract}
RESUMO: O trabalho tem como objetivo socializar algumas reflexões e vivências ocorridas em situação de estágio no curso de Licenciatura em História da Unicruz (Universidade de Cruz Alta, RS). A base teórica de tais reflexões são FONSECA (2004/2007/2011), CAIMI (2008), Barroso (2010), entre outros. A pesquisa caracteriza-se pelo cunho descritivo-qualitativo, tendo como instrumentos a observação e os relatos de experiências. As mesmas nos apontam que os estágios começam a ser vistos não apenas como eixo curricular, mas um espaço significativo na formação de professores.
\end{abstract}

Palavras-chave: Ensino. Formação de Professores. Prática. Teoria.

\begin{abstract}
The paper aims to socialize some thoughts and experiences that occurred during the studants' training in History Course Unicruz (University of Cruz Alta, RS). The theoretical basis of such reflections are Fonseca (2004/07), CAIMI (2008) among others. The research is characterized by having a descriptive and qualitative tools like observation and experience reports. They point out that in stages beginning to be viewed not only as an axis curriculum, but a significant space in teacher education.
\end{abstract}

Keywords: Teaching. Teacher Training. Practice. Theory.

\footnotetext{
1 Doutor em História (PUCRS), Docente da Universidade de Cruz Alta (UNICRUZ) 2002 - 2012; Atualmente docente do Instituto Federal de Educação Ciência e Tecnologia Farroupilha, Câmpus Júlio de Castilhos.

2 Doutora em História (PUCRS), Docente aposentada da Universidade de Cruz Alta (UNICRUZ).
} 


\section{Introdução}

O presente texto pretende socializar algumas reflexões e vivências ocorridas, a partir de 2002, no curso de História (Licenciatura Plena) da Universidade de Cruz Alta. O município de Cruz Alta localiza-se no planalto médio gaúcho no caminho percorrido pelas tropas que partiam do RS com destino a Feira de Sorocaba em São Paulo. Suas origens históricas lusitanas destacam-se em uma área muito próxima à hispânica região missioneira. Seu crescimento está intimamente associado às atividades agropastoris, a viação férrea e a forte presença militar através dos quartéis. Na atualidade, Cruz Alta projeta-se como um polo regional, principalmente, nos planos da saúde e educação. A ideia da construção deste texto nos leva a repensar os limites e possibilidades a respeito do contexto sócio-histórico-cultural local e regional de trabalho e chamar a atenção sobre o significado do Estágio Curricular no processo de formação pessoal / profissional do historiador / docente em História.

A formação de professores além de ser uma demanda da sociedade que busca o desenvolvimento pleno deve ocupar lugar estratégico nas instituições de educação superior. A prática social desenvolvida pelas mesmas devem garantir espaços e ações inclusivas, éticas, humanizadoras e democráticas que sejam capazes de contemplar necessidades regionais $e$ as diversidades. No entendimento de Corsetti (2002, p. 35) as:

Instituições formadoras dos educadores necessitam aprofundar um trabalho que garanta o desenvolvimento não só da consciência social por parte dos futuros professores, mas também de sensibilidade social. Nesse sentido, é fundamental que os novos educadores possam ser preparados para que tenham a compreensão plena do papel da escolarização num mundo com o que atualmente se estrutura nos marcos de um processo de globalização.

É nessa perspectiva que situamos as atividades de ensino, pesquisa e extensão dinamizados no curso de História. As mesmas se efetivaram de forma contextualizada a partir de práticas mediadas por profissionais da História compromissados com a Educação. Como diz Helfer (2010, p. 77): "No sentido de melhor qualificar a profissão e o exercício da docência nos diferentes níveis e 
modalidades da educação básica, visando á garantia de um processo de ensinoaprendizagem de qualidade socialmente diferenciada".

O curso de História $^{3}$ tem suas origens intimamente interligadas à Licenciatura em Estudos Sociais. A sua criação insere-se no contexto econômico, político, social brasileiro e global que começou a ser delineado a partir da segunda metade da década de 1970. As transformações intensificaram-se na década seguinte, mas a nova legislação que norteará a formação de professores ${ }^{4}$ no Brasil, trazendo novos contornos às discussões, começa a emergir no fim da década de 1990.

A formação de professores passa integrar as políticas públicas que começam a emergir na época e os debates que ocorriam no meio a acadêmico tanto no Brasil como no exterior. As discussões ganham novos tempos / espaços gerindo, inclusive, intensas reflexões no âmbito do (s) curso (s) de História. Ao realizar os estudos sobre esse contexto Fonseca (2011, p. 275 - 276) enfatiza:

\begin{abstract}
Nos últimos anos, estamos vivenciando, no Brasil, um processo de revisão, críticas, ampliação e reconhecimento de diversos lugares, processos, sujeitos, saberes e práticas formativas, modos de aprender, ensinar e aprender a ensinar, de formar-se, tornar-se professor de História. A formação, como bem sabemos, não se inicia nem termina nos cursos de Licenciatura. A formação do professor é permanente. Desenvolve-se em diferentes tempos espaços, ao longo da vida dos sujeitos educadores. Ninguém nasce professor, nem há um ponto determinado da vida em que o sujeito torna-se professor. O curso superior habilita, certifica, mas não é o ponto final da formação. Para muitos, marca o inicio de uma trajetória.
\end{abstract}

Sintonizada com as necessidades da sociedade de sua época, a UNICRUZ preocupa-se em formar um profissional inovador, criativo, crítico, reflexivo, pesquisador e interdisciplinar capaz de aliar os saberes científicos ao seu fazer pedagógico. Esse perfil vem ao encontro do pensamento de Oliveira (2007, p. 305) quando diz:

As necessidades do mundo atual exigem a formação de profissionais que acompanhem a evolução do conhecimento, que assumam o

\footnotetext{
${ }^{3}$.Resolução Comum n 09/98, 25/8/1998; Reconhecido pela Portaria MEC 3897/2003; DO 23/12/2003; Renovação do Reconhecimento Portaria n 1655/2010, DO 08/10/2010.

${ }^{4}$ Sobre ver: Revista Educação - Formação de professores, v. 31, no 03. Porto Alegre: PUCRS, set/dez/2008
} 
trabalho de forma consciente e crítica e que revelam características capazes de assegurar participação e compromisso político e cidadania. Tais indicadores devem orientar a prática do professor, tendo em vista assegurarem a formação do ser histórico, construtor da sociedade em que vive.

Pensar a formação de professores é algo que exige intensas reflexões, atitudes e decisões que possam contribuir para a renovação das práticas sociais. Com base nas premissas anteriormente mencionadas é que decidimos pela construção deste texto que enfoca as nossas convicções além das vivências interativas desenvolvidas ao longo do processo. O mesmo é dinamizado a partir de atividades que segundo Lautier (2011, p. 51) são de delinear "as operações cognitivas mobilizadas nas aulas são o guardião da identidade profissional, profundamente disciplinar, dos professores, e das dificuldades encontradas se traduzem frequentemente por uma defasagem entre as intenções e os atos".

\section{Desenvolvimento}

Com o intuito de promover a atualização contínua do conhecimento, articulação teórica e prática, diálogos, orientações, flexibilidade, investigações, desenvolvimento de habilidades, atitudes e valores, convivência com questões éticas, sociais e profissionais bem como melhorar o processo de formação do professor de História é que propomos esse texto. Em nosso entendimento o enriquecimento desse processo passa pela formação de um professor pesquisador. Ao falar em aproximações entre ensino e pesquisa lembramos Freire (2000, p. 32) quando o mesmo diz:

Não a ensino sem pesquisa e pesquisa sem ensino. Esses que fazeres se encontram um no corpo do outro. Enquanto ensino continuo buscando, reprocurando. Ensino porque busco, porque indaguei, porque indago e me indago. Pesquiso para constatar, constatando, intervenho, intervindo educo e me educo. Pesquiso para conhecer o que ainda não conheço e comunicar ou anunciara novidade.

Na continuidade de seu pensamento Freire (2000, p. 32) ressalta: 
Fala-se hoje, com insistência, no professor pesquisador. No meu entender o que há de pesquisador no professor não é uma qualidade ou uma forma de ser ou de atuar que se acrescente à de ensinar. Faz parte da natureza da prática docente a indagação, a busca, a pesquisa. O de que se precisa é que, em sua formação permanente, o professor se perceba e se assuma, porque professor, como pesquisador.

Em meio às crises e reflexões a respeito da Educação cresce a importância dos processos de formação inicial e continuada de professores. Nesse sentido retorna-se a ideia de formar professores que além de serem capazes de mediar o processo de construção do conhecimento sejam eficientes pesquisadores. O papel da pesquisa na formação de professores como enfatiza André (2006, p. 123) é propiciar o:

Desenvolvimento de sujeitos autônomos, livres e emancipados. A pesquisa pode tornar o sujeito - professor capaz de refletir sobre a sua prática profissional e de buscar formas (conhecimentos, habilidades, atitudes, relações) que o ajudem a aperfeiçoar cada vez mais seu trabalho docente, de modo que possa participar efetivamente do processo de emancipação das pessoas.

Os desafios da sociedade contemporânea requerem que o professor da educação básica seja um cidadão completo capaz de atender de forma eficaz as necessidades deste novo tempo. É natural que este "completo" passe, necessariamente, pelos aportes teóricos, pelos valores identitários, humanos e de cidadania, pelos aspectos pedagógicos e por atitudes investigativas, inovadoras e interdisciplinares no processo de ensinar e aprender história.

Ao se referir a complexa tarefa de ressignificar a identidade do professor, por sua vez, Bittencourt (2004, p. 16 - 17) esclarece:

O ensino, atividade característica dele, é uma prática social complexa, carregada de conflitos de valor e que exige posturas étnicas e políticas. Ser professor requer saberes e conhecimentos científicos, pedagógicos, educacionais, sensibilidade, indagação teórica e criativa para encarar as situações ambíguas, incertas, conflituosas e, por vezes, violentas, presentes nos contextos escolares e não escolares. É da natureza da atividade docente proceder à mediação reflexiva e crítica entre as transformações sociais concretas e a formação humana dos alunos, questionando os modos de pensar, sentir, agir e de produzir e distribuir conhecimentos. 
A formação da identidade do professor bem como o seu processo formativo são aspectos que se prolongam pela vida inteira. Para que isso ocorra é imprescindível que esse processo se efetive aliado a novas propostas curriculares no âmbito da academia. Nessa perspectiva, é salutar que as práticas de ensino, pesquisa e extensão sejam criativas, dialógicas, contínuas, autônomas e capazes de anunciar novas posturas que venham, como defende Clotet (2011, p. 15), "compatibilizar sua formação acadêmica com as exigências do mundo laboral".

Esses requisitos precisam ser presenças indispensáveis no âmbito do processo formativo qualificado do professor. A identidade epistemológica e profissional do mesmo é simultânea e realizam-se no sentido teórico e na prática social. Na formação de professores, as atividades de ensino e pesquisa de acordo com Bittencourt (2004, p. 19) devem: "Considerar a pesquisa como principio cognitivo, investigando com os alunos a realidade escolar, desenvolvendo neles essa atitude investigativa em suas práticas profissionais e assim tornando a pesquisa também princípio formativo na docência".

No momento em que elaboramos esse texto encontramos respaldo teórico em um documento recente do Ministério da Educação que traz orientações curriculares para o ensino de ciências humanas no Ensino Médio. Ao se referir aos professores de História as $\operatorname{OCEM}^{5}$ (2006, p. 93) assim expressa:

A formação sólida dos profissionais que atuam no sistema de ensino é condição imprescindível para implantação de reformas educacionais. Daí a responsabilidade das instituições que se dedicam á formação superior de historiadores-professores em estruturar propostas e práticas curriculares que visem os domínios não apenas do conteúdo, das teorias e metodologias do conhecimento histórico, mas também ao domínio das proposições teóricas e metodológicas a respeito do processo ensino/aprendizagem da História. A formação básica constantemente realimentada pela formação permanente fornecerá a consistência necessária para que os professores-historiadores desempenhem suas funções na elaboração e na execução do projeto pedagógico da escola.

5 Orientações Curriculares para o Ensino Médio. História. Ciências Humanas. v. 3 Brasília: MEC/Secretaria de Educação Básica, 2006. 
Atualmente, escola e sociedade vêm passando por transformações em razão da interdependência planetária e globalização da informação, o que faz com que pesquisadores da área da educação dediquem parte de seus estudos à questão da formação de professores, sobretudo a formação continuada. Nesse caso priorizamos as nossas indagações a respeito da formação do professor de História.

Em meio a um quadro dominado pela mundialização e/ou globalização para pensar a formação de professores, torna-se necessário uma reflexão sobre as relações entre o global e o local, a tradição e a modernidade, entre o espiritual e o material, teoria e prática, ensino e pesquisa bem como sobre o desenvolvimento de capacidades de assimilação e construção do conhecimento em um determinado espaço-tempo. Na realidade esse processo deve responder aos desafios da rapidez de um mundo em mudança a partir dos princípios como ética, cultura, diversidade, cognição, autonomia, comunicação, inclusão, responsabilidade pessoal e profissional, acessibilidade no tempo e no espaço, enfim, como ressaltam Bastos e Quadros (2005, p. 55): "Uma formação docente plural que ajude a processar a multiplicidade de desafios de uma sociedade complexa e multicultural, para realizar uma prática reflexiva e transformadora, compreendendo-se como sujeito da História no/do cotidiano escolar/educacional".

Hoje no panorama da educação brasileira, coexiste uma enorme diversidade de alternativas de ensinar, aprender e formar professores que irão mediar o processo ensino-aprendizagem na Escola Básica. No universo das licenciaturas observamos uma multiplicidade de currículos, programas e concepções ideológicas, políticas, teóricas e metodológicas. Essa diversidade inspira pesquisas nos diferentes campos do conhecimento e da educação.

$\mathrm{Na}$ prática torna-se preciso a dinamização de um processo que exige investigação, sensibilidade e postura crítica entre os alunos e professores durante as ações investigativas e formativas de construção de saberes nos diversos espaços-tempos culturais e educativos. Torna-se cada vez mais urgente, pensar a essencialidade de formarmos um professor pesquisador, crítico, pensador, articulador entre os conhecimentos gerais e específicos, cidadão e capaz de coordenar um processo interdisciplinar, aberto, construtivo e dinâmico 
de elaboração de novos saberes, conforme Tardif (2002) Nesse contexto a interdisciplinaridade além de precisar ser considerada como uma urgência na contemporaneidade é fundamental que seja considerada uma "atitude" e pelo viés do pensamento de Fazenda (2000). Por outro ângulo e indo ao encontro dessas ideias recordamos Trindade (2008, p. 82) quando o mesmo assim refere:

A prática interdisciplinar pressupõe uma desconstrução, uma ruptura com o tradicional e com o cotidiano tarefeiro escolar. 0 professor interdisciplinar percorre as regiões fronteiriças onde o "eu" convive com o "outro" sem abrir mão de suas características, possibilitando a interdependência, o compartilhamento, o encontro, o diálogo e as transformações. Esse é o movimento da interdisciplinaridade caracterizada por atitudes ante o conhecimento.

Nessa perspectiva, entendemos que as práticas pedagógicas devem ocorrer ao longo do processo formativo como algo social, histórico e culturalmente elaborados. Assim recorremos a Fonseca (2007, p. 152) quando diz:

\footnotetext{
Uma proposta no decorrer do processo de formação inicial que tenha, como eixo vertebrador, a reflexão na e sobre a prática conduz às transformações necessárias à produção de saberes e práticas que possibilitam as incorporações/superações de forma dinâmica e dialética.
}

No processo interativo entre formadores e formandos torna-se cada vez mais necessário que sejam contempladas as dimensões teóricas, técnica, e instrumental. Nesse sentido, é fundamental que ocorram diálogos e aproximações entre os fundamentos científicos, pedagógicos e políticos, assegurando dessa forma a formação de professores capazes de articular saberes e práticas em uma realidade complexa, desigual, plural e adversa.

A política educacional brasileira faz alusão à profissionalização de professores baseada no desenvolvimento de competências, destacando o saber prático docente, o "saber fazer", e, por conseguinte estabelecendo estreitas relações com o sistema produtivo mundial.

O desafio maior às instituições formadoras de docentes continua sendo a formação do professor, sem cair no marasmo de formar simplesmente para 
"saber fazer", mas para "saber explicar o que faz", em um processo dialético entre teoria-prática, sendo a pesquisa um eixo pedagógico básico, sendo essencial a possibilidade de um constante (re)fazer, (re)construir de saberes docentes. A dinamização desse processo precisa aliar a educação na sua globalidade e estreitar relações entre a teoria e a prática educativa. As práticas precisam ser entendidas enquanto atividade humana permeada pela dialogicidade, teoria, reflexão, conscientização e autonomia. Nessa perspectiva, as mesmas vão conceder licença à práxis que no entendimento de Rossato (2008, p. 331) "pode ser compreendida como a estreita relação que se estabelece entre um modo de interpretar a realidade e a vida e a consequente prática que decorre desta compreensão levando a uma ação transformadora". Nessa linha de raciocínio entendemos a práxis como algo essencial na formação humana e no processo de formar professores.

Nóvoa (1995, p. 25), por sua vez, ao referir-se à formação de professores propõe através da prática um processo reflexivo sobre a profissão:

A formação não se constrói por acumulação (de cursos, de conhecimento ou de técnicas), mas sim através de um trabalho de reflexividade critica sobre as práticas e de (re)construção permanente de uma identidade pessoal. Por isso é tão importante investir na pessoa e dar um estatuto ao saber da experiência.

A formação é na verdade, conforme Pimenta (2000, p. 29) uma autoformação, uma vez que os professores reelaboram os saberes iniciais em confronto com suas experiências práticas, cotidianamente vivenciadas nos contextos acadêmicos. É nesse confronto e num processo coletivo de troca de experiências e práticas que os professores vão construindo seus saberes como praticum, ou seja, aquele que constantemente reflete na e sobre a prática.

Percebemos e acreditamos que a formação docente na dupla perspectiva do professor enquanto indivíduo (aspecto pessoal), inserido num coletivo (aspecto organizacional escolar), em que a construção de saberes e fazeres ocorre na dimensão da ação-reflexão-ação, enquanto processo de investigação e por consequência investigação-formação. Ao tratarmos desses aspectos vamos encontrar respaldo em Isaia e Piveta (2008, p. 261) quando afirmam que no momento 
Em que o professor identifica o espaço de trabalho como um ambiente de formação docente e que este acontece paralelo a formação de aluno, a troca de conhecimentos e a socialização de saberes, a prática pedagógica torna-se um processo de construção que é permanente, em que a ética, o respeito, a humildade e o comprometimento de cada professor viabilizam a construção desse importante universo formativo.

$\mathrm{Na}$ realidade os sujeitos envolvidos com o curso de História e o grupo de pesquisa "Estudo, Ensino e Pesquisa em História" são comprometidos em propor ações formativas de caráter cientifico, histórico e pedagógico. As leituras e experiências vivenciadas nos levam a acreditar, cada vez mais, na necessidade de um referencial teórico atualizado e de práticas de ensino e pesquisa capazes de demonstrar resultados que evidenciem outras alternativas. No caso especifico da formação do professor de História o projeto deve contribuir conforme Fonseca e Couto (2009, p. 108) para a: "Formação de um profissional qualificado para o exercício da pesquisa, em consonância com as novas tecnologias, que domina competências e habilidades para o exercício da profissão de historiador e seja capaz de atuar no mundo globalizado".

Nessa perspectiva recorremos a Cerri (2011, p. 18) que, por sua vez, argumenta:

se o ensino de história implica o gerenciamento dos objetivos curriculares e das concepções de tempos e de história que os alunos já trazem consigo desde fora da escola, então o professor de história definitivamente não é tradutor de conhecimento erudito para o conhecimento escolar, um simplificador de conteúdos. É, sim, um intelectual capaz de identificar os quadros de consciência histórica subjacentes aos sujeitos do processo educativo inclusive o seu próprio - de assessorar a comunidade na compreensão crítica de tempo, da identidade e da ação na história.

Essas reflexões não contemplam a amplitude da temática. Pelo contrário, suscitam novas investigações sobre a formação de professores e anunciam o que recomenda Lima (2008, p. 137) que a mesma precisa ser:

Redimensionada, ou a escola corre o risco de entrar em um processo de esvaziamento de sua função social. O professor que antes não sentia necessidade de refletir sobre si mesmo - sobre seu saber, seu fazer e seu saber - fazer - agora precisa não só dessa 
reflexão, mas dessa reflexão no espaço coletivo. O professor que saía se sua formação inicial "pronto" para exercer sua função agora precisa cada vez mais do conhecimento. Conhecimento sobre seu trabalho, sobre o trabalho escolar e sobre si mesmo.

A universidade brasileira está passando por um momento de certezas e incertezas. A mesma começa a assumir um novo patamar teórico-metodológico, criando assim uma nova relação entre ensinar e aprender na qual a cognição, o afeto e a ética sejam companheiros de uma significativa jornada.

O caminho proposto é o aprimoramento da qualidade do processo formativo. Os diálogos e as atividades de ensino e/ou investigação viabilizarão intercâmbios entre sujeitos, ideias, saberes, valores, tradições, símbolos, significados, experiências bem como a elaboração de recursos didáticos estratégicos para a qualificação do processo ensino-aprendizagem em história.

Retornando o foco maior de nosso texto, passamos a partilhar com o leitor parte das nossas vivências enquanto orientadores dos Estágios no Curso de História da Universidade de Cruz Alta (Unicruz/RS). As mesmas ocorreram no período compreendido entre o ano de 2002 a 2012.

A base curricular do curso de História é constituída, conforme a legislação, pelas disciplinas de caráter teórico, histórico e científico específicos da área, as disciplinas de formação didático-pedagógica, as optativas, os $\operatorname{TCCs}^{6}$ e as atividades complementares. Nessa lógica, esclarecemos que a sua organização curricular está em consonância com a Resolução CNE / CP no 02/2002, respaldada no Parecer CNE / CP no 28 / 2001, o qual institui a duração e carga horária dos cursos de Licenciatura. O mesmo estabelece a exigência da integralização de, no mínimo, 2800 (duas mil e oitocentas) horas, nas quais o entrecruzar teoria e prática deve ser salvaguardado no Projeto Pedagógico e atender as dimensões dos componentes comuns:

[...] I - 400 (quatrocentas) horas de prática como componente curricular, vivenciadas ao longo do curso;

II- 400 (quatrocentas) horas de estágio curricular supervisionado a partir do início da segunda metade do curso;

III - 1800 (mil e oitocentas) horas de aulas para os conteúdos curriculares de natureza científico-cultural;

\footnotetext{
${ }^{6}$ Trabalho de Conclusão de Curso
} 
IV - 200 (duzentas) horas para outras formas de atividades acadêmico-científico-culturais.

Parágrafo único: os alunos que exerçam atividade docente regular na educação básica poderão ter redução da carga horária do estágio curricular supervisionado até o máximo de 200 (duzentas horas). (BRASIL, 2001, p. 16)

Em meio a essa organização, as "disposições legais" dão origem às atividades relativas ao campo de estágio ${ }^{7}$ como componente curricular obrigatório. Ao verificarmos como acontece a articulação teoria e prática percebemos que a mesma ocorre em sintonia ao que esclarece o Parecer CNE / CP no 09 / 2001: "A prática na matriz curricular não pode ficar reduzida a um espaço isolado que a reduza ao estágio como algo fechado em si mesmo e desarticulado do restante do curso".

As dinâmicas implementadas no Curso de História, originadas a partir da confluência entre os aportes teóricos e as situações experimentais fortalecem a construção qualificada do conhecimento, bem como as relações dialéticas entre a

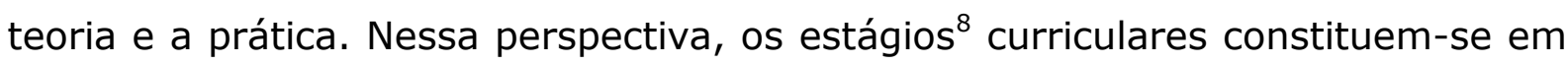
desafios do ponto de vista teórico e prático, tanto para o acadêmico em processo de formação, como para o professor orientador.

Cabe ressaltar que o Estágio, essencial para o acadêmico alcançar a Licenciatura Plena em História, é um espaço social que exige conhecimento da realidade, postura epistemológica, reflexões teóricas, aproximação entre os saberes acadêmicos e os saberes escolares, planejamento, alternativas metodológicas, recursos didáticos adequados, acompanhamento e avaliação. Por outro lado, é um momento significativo de construção da identidade docente. Como defende Rodrigues (2004, p. 66) é uma:

Situação transitória de preparação profissional - é um aprendizado mediante exercício prático. É cada uma das sucessivas atividades projeto, planejamento, execução, construção do relatório - nas quais o estagiário tem sua ação orientada e supervisionada por um professor.

\footnotetext{
7 Sobre ver: PICONEZ, Stela C. Bertholo (coord). A Prática de Ensino e o Estágio Supervisionado. ga ed. Campinas: Papirus, 2003.

8 ABDALLA, Maria de Fátima Barbosa. A Relação Teoria e Prática no Campo de Estágio. Revista de Educação. No 26. Campinas: PUC / Campinas, jan/jun / 2009. p. 53-52.
} 
O estágio deve propiciar ao aluno um contato com a realidade que vivenciará como profissional. Essa é a concepção que estamos discutindo e consideramos que deva prevalecer e é nessa perspectiva que estamos trabalhando e adotando às práticas que garantam uma experiência ativa e dinâmica.

O parecer CNE / CP n० 28 / 2001 quando trata do estágio assim se refere "é o momento de efetivar, sob a orientação de um profissional experiente, um processo de ensino-aprendizagem que se tornará concreto e autônomo quando da profissionalização deste estagiário".

O estágio é um momento de prática e cultura onde o acadêmico, em processo de formação, é desafiado a pensar, ensinar e agir. As suas ações precisam ser permeadas por saberes, valores e atitudes inovadoras, contribuindo, como diz Bittencourt (2004. P. 13-21) para a "mediação entre os significados do saber no mundo atual e aqueles dos contextos nos quais foram produzidos". É recomendável que o mesmo seja capaz de refletir, rever ideias, encontrar soluções para situações ambíguas, propor diálogos, formar consciências, sugerir situações práticas, pois, como lembra Fonseca (2004, p. 84) "ensinar história é partilhar saberes, contribuindo para a formação de uma determinada maneira de ver e compreender o mundo".

A essa altura é pertinente trazer, para o texto, a contribuição de Pimenta e Lima (2004, p. 132) quando as mesmas elucidam o encontro entre a teoria e a prática em situação de estágio. Segundo as autoras, isto ocorre quando o professor no:

Espaço do estágio tem a possibilidade de se reconhecer como sujeito que não apenas reproduz o conhecimento, mas também pode tornar-se seu próprio trabalho de sala de aula em um espaço de práxis docente e de transformação humana. É na ação refletida e no redimensionamento de sua prática que o professor pode ser agente de mudanças na escola e na sociedade.

Na realidade o estágio é um espaço-tempo rico em intencionalidades onde o acadêmico deve pautar as suas ações na mediação crítico-reflexiva entre as mutações da sociedade e o processo de formação humana, intelectual e cidadã de seus alunos. É um momento significativo onde o estagiário estabelece uma cumplicidade com o aprendiz, originando-se assim o que acreditam Tardif e 
Lessard (2005, p. 267) "um conjunto de interações personalizadas com os alunos, a fim de obter participação deles em seu próprio processo de formação e atender às suas diferentes necessidades".

O estágio é uma oportunidade que aproxima o aprendiz em formação com a realidade do sistema educacional. Além de diagnosticar a realidade do contexto onde se realiza a práxis que de acordo com Rossato (2008, p. 331) "é uma síntese entre teoria - palavra e ação." O mesmo estabelece relações críticas e reflexivas pautadas nos princípios da ética, justiça, autonomia, inclusão, diversidade, participação responsável e interdisciplinaridade.

A contemporaneidade, plena em transformação, requer uma escola onde as atividades socioeducativas e culturais previstas em seu projeto pedagógico e desenvolvidas pelos seus professores conforme Bittencourt (2004, p. 17) deve proceder "a mediação reflexiva e crítica entre as transformações sociais concretas e a formação humana dos alunos, questionando os modos de pensar, sentir, agir e de produzir e distribuir conhecimentos".

Para compreendermos melhor os propósitos dos estágios curriculares efetivados no Curso de História da UNICRUZ, passamos a seguir a anunciar como os mesmos transcorrem. É salutar que seja garantida uma eficácia pedagógica e isto exige que durante os mesmos ocorra um continuum de orientações, investigação, exercício do saber e do conhecimento adquirido durante o curso, discussões, reflexões, troca de experiências, sugestões, vivências, acompanhamento e avaliação da e na Universidade / Escola. O entendimento que temos a respeito do estágio nos leva a empreender iniciativas criativas e desafiadoras, mas ao mesmo tempo respaldadas pelos estudos realizados por Fonseca (2007, p. 153) a respeito da articulação estreita entre saberes e prática pedagógica no âmbito da História. A autora concebe os seguintes objetivos da prática pedagógica nos cursos de formação de professores:

- Articular teoria e prática no contexto da educação escolar básica, saberes disciplinas e pedagógicos;

- Criar condições para que os futuros profissionais da educação possam vivenciar diversas situações educativas em diferentes realidades e contexto socioeducacionais; 
- Propor situações que ampliem as oportunidades do campo de trabalho, por meio da compreensão das relações entre a prática e o contexto social;

- Compreender as questões da pluralidade cultural e diversidade social e suas implicações no contexto escolar;

- Promover situações interativas que possibilitem a ressignificação das experiências;

- Utilizar diferentes metodologias e tecnologias de ensino, de modo a propiciar ao futuro profissional suportes necessários para o exercício da prática docente;

- Organizar a prática orientada baseada no princípio ação-reflexão-ação, articulando teoria e prática em todos os momentos do trabalho;

- Compreender a avaliação como momento do ensino-aprendizagem, subsídio para o replanejamento das atividades;

- Valorizar todas as dimensões do trabalho pedagógico do professor no contexto escolar;

- Valorizar os aspectos éticos, políticos e estéticos a serem observados na elaboração e no desenvolvimento das propostas pedagógicas;

- Enfatizar o processo de construção e reconstrução da identidade profissional no processo de formação teórico-prático;

- Participar dos processos de elaboração, desenvolvimento e avaliação dos projetos de ensino e história.

Somos conscientes da amplitude das posições de Fonseca (2007). Nesse sentido, é nítida a consciência do significado e urgência de contribuirmos teórica e metodologicamente para a formação de um profissional que como recomenda a ANPUH $^{9}$ e avalizam Corsetti / Canan (2010, p. 52 - 53), ou seja, "tenha qualidades para ser um excelente professor e um excelente trabalhador em outros espaços que exijam o conhecimento historiográfico." O grande compromisso é com a formação de professores / pesquisadores capazes, no exercício da prática, de construírem um planejamento permeado pela sintonia dos objetivos, interfaces dos conteúdos e pela interatividade de ambos a partir de atividades criativas, críticas, lúdicas, emancipatórias e interdisciplinares. Para que isso torne-se uma realidade constituída, a intenção é entrecruzar olhares,

\footnotetext{
${ }^{9}$ Associação Nacional dos Professores de História
} 
teorizar, estabelecer diálogos entre sujeitos, rever discursos, redefinir possibilidades, redimensionar práticas e por isso recorremos a Zamboni e Mesquita (2008, p. 159) quando definem que "a docência, o ensino e a reflexão sobre a formação de professores de História fazem parte do ofício do historiador".

Dando continuidade, passamos a tecer uma narrativa sobre as experiências de estágios no curso de História. As mesmas, além de atender aos aspectos legais, propiciam situações inusitadas, até então, para os acadêmicos.

Os primeiros contatos com a Educação Básica foram mantidos através da participação nas atividades propostas pelas disciplinas de Prática Docente. 0 Estágio Curricular Supervisionado I (ECS I) ocorre no $5^{\circ}$ período através da investigação da realidade escolar e da turma onde ocorrerão, efetivamente, os primeiros exercícios da docência em História de $5^{a}$ a 8 asérie e/ou do $6^{\circ}$ ao $9^{\circ}$ ano do Ensino Fundamental.

A intenção básica é que o estágio se constitua um campo de vivência social tendo a prática pedagógica como princípio integrador. Essa prática se insere como parte deste tecido que nos propicia as vivências enquanto sujeitos capazes de atuar criativamente em situações complexas na construção de novos saberes. Nessa perspectiva, recorremos a Gonçalves (2011, p. 01) quando diz:

Os estágios são elementos fundamentais na formação do aluno dos cursos de licenciaturas, representam um momento no qual os futuros docentes entram em contato com estrutura de ensino: tanto na sua parte administrativa, isto é, a direção e a orientação pedagógica, como também com os professores e alunos. Em seu contato com a escola os estagiários vão tomando consciência das reais condições de existência da escola pública, como ela funciona, qual sua lógica, percebem as formas a partir das quais se realizam nesse coletivo chamado escola as práticas cotidianas. Observam o que tem sentido e o que é valorizado pelos sujeitos, professoras, professores e funcionários, que lá passam a maior parte de suas vidas úteis.

O ECS I exige que o acadêmico esteja imbuído de um espírito investigativo cujos resultados apontam caminhos para o conhecimento do contexto e para o planejamento da prática. Esse exercício, com certeza, aproxima o ensino e a pesquisa, pois, como defende Martins (2010, p. 9) "aprende-se com que se encontra ou com quem nos encontramos; inversamente, aprendem conosco 
aqueles com quem convivemos e, a partir de nossas ações concretas, produz-se no mundo vivído realidade transformada. Os processos de mediação são constantes e intercambiáveis".

Logo após a primeira aula do componente ECS I, quando ocorre a apresentação, socialização e replanejamento do mesmo, acontece uma reunião onde o professor orientador informa sobre a dinâmica processual de primeiro estágio. Nesse momento dinamiza-se a apresentação das informações a respeito das observações, instrumentos a serem utilizados na pesquisa, da sistematização de dados e informações que irão subsidiar a organização do planejamento e / ou do Projeto a ser implementado no ECS II.

Além da entrevista com representante da Equipe Diretiva e com o professor da turma o acadêmico utiliza um roteiro de orientação, geralmente, tanto nas entrevistas quanto nas investigações no Regimento Escolar, no Projeto Político Pedagógico, no Plano de Estudos da disciplina, bem como junto à turma na sala de aula. As observações e a pesquisa constituem-se em atividades básicas do ECS I. As mesmas desvelam dados e informações em relação ao contexto socioeconômico e cultural onde a escola está inserida; objetivos e atividades a serem desenvolvidas no recorte temporal em questão; os conteúdos a serem abordados; as habilidades e competências em processo de construção; os valores a serem repensados, a sistemática de avaliação; os recursos didáticos disponíveis, o referencial bibliográfico decorrente da necessidade específica de cada estagiário conforme o projeto a ser desenvolvido.

Esse estágio e os demais são vitais no processo formativo do professorando constituindo-se no entendimento de Caimi (2008, p. 290) em um:

Processo investigativo-reflexivo sobre a prática que não pode prescindir, sob qualquer pretexto, da efetiva interlocução com um aporte teórico que nos permita constituir um círculo virtuosoespiralado (e não vicioso) de ação-reflexão-ação, operando transformações tanto no sujeito (professorando) quanto suas ações docentes.

Dessa forma, a sistematização dos dados e informações agilizam a elaboração do Projeto de Ensino respeitando o contexto cultural da escola, a valorização dos conceitos e conhecimentos a serem elaborados e assimilados pelos alunos, bem como a possibilidade de gerir atividades de ensino que 
ensejam o desenvolvimento de habilidades e competências essenciais na prática de Ensino de História. Nessa perspectiva, começa a ser delineado o projeto que é lançado no ECS II.

No ECS II o acadêmico escolhe trabalhar de $5^{\mathrm{a}}$ a $8^{\mathrm{a}}$ série e/ou do $6^{\circ}$ ao $9^{\circ}$ ano do Ensino Fundamental durante um bimestre ou trimestre, quando o acadêmico chega ao $6^{\circ}$ período do Curso de História. É o momento em que o professor estagiário, enquanto sujeito histórico recorre às leituras realizadas das políticas públicas, da produção historiográfica / educacional e dos processos culturais que assinalam o cotidiano social contemporâneo. É quando ocorre a prática docente entendida como uma prática sociocultural onde vivem e se contrapõem sensibilidades, atividades, contexto social de atuação, ética, concepções de mundo, habilidades, formas dialéticas do pensar e do ser, conhecimentos e experiências de vida. Com esta postura propõe a superação da dicotomia teórica e prática. Portanto considera-se que não há mais possibilidade de dissociar conhecimento e prática. Esses elementos apontam o que Corsetti / Canan (2010, p. 52) defendem "substitui-se o professor passivo, pronto, acabado, com saberes permanentes, por um professor que é sujeito de seu processo de conhecimento e como tal pode contribuir na formação de novos sujeitos".

Nesse sentido o professor precisa ser dinâmico, reflexivo, interdisciplinar e capaz de planejar atividades a serem efetivadas a partir de metodologias de ensino criativas, lúdicas e contextualizadas com a produção de textos, debates, estudos de imagens e fotografias, elaboração de história em quadrinhos, montagem de peças de teatro, análise de filmes e documentários, saídas de campo, montagem de jogos, visitas orientadas a lugares históricos e a museus, trabalho com mapas, elaborações de linha de tempo ilustradas, etc. dessa forma contribuindo para que a sala de aula passe a constituir- se um espaço de relações interpessoais capazes de gerir convivências fraternas, aprendizagens significativas, respeito mútuo, cultivo de autonomia, trocas de experiências, de elaborações conceituais enfim tornando a sala de aula em espaço-tempo social e cultural onde são construídos significados e saberes. Para que esse processo seja efetivado é pertinente lembrar o que recomendam Rosa/Veit (2011, p. 309 310) 
As inovações metodológicas exigem que o professor, além de dominar o conteúdo, seja capaz de prever a realização da atividade, passo a passo, providencie e organize os materiais com antecedência, tenha presença de espírito para contornar situações inusitadas e seja capaz de convencer os alunos a participar. Parece importante também, que o estagiário já tenha conquistado a confiança dos alunos de modo a que eles tenham a certeza de que não serão expostos a nenhuma situação em que possam ser ridicularizados por sua inépcia. Além disso, a apresentação da atividade a ser realizada precisa ser clara para que os alunos saibam exatamente o que precisarão fazer. Também é importante que 0 professor demonstre o quanto aquela tarefa diferente contribui para o aprendizado".

Nesse estágio, assim como nos vindouros, além das orientações costumeiras por parte do professor responsável pelo ECS II, o estagiário recebe o apoio do professor titular da turma. Esse convívio estabelece laços de amizade que acabam reforçando o compromisso em prol da superação da dicotomia entre teoria e prática, tornando a aula um lócus de ensinar e aprender História. É a partir dos anos finais do ensino fundamental que se ampliam essas possibilidades, abrindo, segundo Pereira / Graebin (2010, p. 172) um espaço no qual "a História possa ser o instrumento da ação social; um instrumento capaz de equipar as novas gerações com as ferramentas para ler as representações que circulam na sociedade do momento presente e que circularam no passado."

Durante as sessões de orientações, percebemos inquietudes e certo receio por parte de alguns estagiários, o que na maioria das vezes não se constata por ocasião da visita de acompanhamento. Ao longo desse processo procuramos evitar aquele "clima de supervisão". Ao contrário, a ideia é estabelecer laços que chamamos "cumplicidade comprometida" em prol de uma prática pedagógica interessante e eficiente e nesse caso, como alerta Meinerz (2010, p. 205) a:

Prática se redimensiona quando a gente atua com os jovens e começa a compreendê-los não apenas como alunos. Esse aprendizado é difícil, pois sugere transpor nossa função e formação original, que é, embora precariamente, lidar com o conhecimento abstrato, essência de um modelo ainda permanente de escola e de currículo.

O ECS III é mais uma importante oportunidade de experienciação docente do acadêmico em formação. Este estágio ocorre durante um bimestre ou 
trimestre com uma turma das três séries do Ensino Médio. O ECS III é antecedido por um período de observação e acesso às informações importantes para a constituição de um estudo sobre o contexto social e cultural no qual a escola se insere. Os procedimentos e as orientações são realizados de forma muito semelhante aos estágios anteriores e já explicitado neste estudo.

As experiências dos estágios II e III nos reportam para as ideias de Martins (2011, p. 83 - 91) tanto ao defender que "a história se faz pelo agir humano no tempo e no espaço social". Por outro lado Martins apresenta a sua pertinente preocupação com "a qualidade controlável dos conteúdos produzidos e utilizados e com a responsabilidade de docentes e aprendizes para consigo e para com os demais". No seu entendimento "o ensino de história é, com isso, simultaneamente profissão e missão".

Ao tratar de situação semelhante Arruda (2011, p. 139) nos traz interessante passagem de Lave e Wenger (1991) ao estudarem sobre aprendizagem. Para estes autores "a aprendizagem das pessoas ocorre quando elas participam de uma prática social. Os indivíduos aprendem não só por intermédio da execução de certas atividades, mas, também, pelo estabelecimento de relacionamentos sociais com determinados sujeitos, em circunstancias específicas. Eles afirmam que as atividades, tarefas e os entendimentos que as pessoas formam sobre as coisas possuem significado em sistemas mais amplos, os quais são desenvolvidos em comunidades sociais. Desenvolvendo a abordagem da aprendizagem situada os autores defendem que os aprendizes aprendem com os outros aprendizes e, participando da prática, negociam significados".

Nas vivências como orientadores desse estágio percebemos a preocupação dos professorandos na fase de construção dos projetos e na elaboração das aulas. Outro aspecto revelado é a seriedade com que as escolas tratam os conteúdos a serem abordados, tanto no sentido do aprofundamento quanto na urgência em vencê-los na pequena carga-horária da disciplina. Essa preocupação tem a ver com o nível de exigência dos vestibulares nas universidades federais e na prova do Enem. 
Felizmente desde que começamos atuar como orientadores desse estágio não tivemos nenhuma dificuldade nesse sentido. Por outro lado, verifica-se a dificuldade quanto à elaboração de instrumentos de avaliação e a tipologia das questões propostas. Por isso, já nas disciplinas de Prática Docente e no próprio ECS I, vimos desenvolvendo estudos sistemáticos a respeito dos aportes teóricos e situações práticas de avaliação. Em diferentes ocasiões nos desafiamos a propor oficinas para a elaboração ou análise de diferentes questões, as quais podem constar nestes tipos de concurso. Essa postura conflui com o pensamento de Soares / Ribeiro (2008, p. 93) quando abordam que "a avaliação constitui-se em um instrumento de investigação incessante das dificuldades do estudante e de dinamização de novas oportunidades de conhecimentos".

Outra forma cooperativa que ocorre nos ECS II e III é a orientação para que os estagiários não limitem a sua prática à memorização, ao factual, ao linear e ao uso intenso do livro didático. Acreditando que é possível estabelecer uma nova concepção de ensino-aprendizagem em História, gestado a partir do contexto histórico-cultural, das relações espaço-temporais, da construção do conhecimento e da diversidade de temáticas e fontes ${ }^{10}$ propondo atividades crítico-reflexivas e interdisciplinares. Além da adaptação das práticas às necessidades sociais e econômicas locais/regionais é essencial que a interdisciplinaridade tenha como seu nascedouro o trabalho em equipe. O desafio sugerido vêm ao encontro do argumento de Japiassu (1976) quando o mesmo defende que a interdisciplinaridade é um campo fértil para " exploração das fronteiras das disciplinas". Essas atitudes trazem de volta as orientações efetivadas durante a Prática Docente IV (Metodologia do Ensino de História) como as para a utilização de novas fontes e linguagens - importantíssimas para que se dinamize uma prática pedagógica inovadora. Nesse sentido, recuperamse as ideias defendidas por Soares (2008, p. 263) quando este autor diz:

É a atividade do professor frente às vicissitudes do mundo contemporâneo que irá possibilitar a elaboração consciente das atividades de ensino que levem em consideração a realidade e o

\footnotetext{
${ }^{10}$ ABUD, Katia Maria et. ali (orgs). Ensino de História. Idéias em Ação. São Paulo: CENGAGE, 2010. LAMBER, Peter; SCHOFIELD, Phillipp. História - Introdução ao Ensino e a Prática. Porto Alegre: Penso / Artmed, 2011.
} 
desenvolvimento intelectual dos alunos, com vistas a um mundo mais justo e igualitário.

O ECS IV é um estágio que inova ao propor a prática em espaços de História e Memória, como arquivos, museus, centros culturais, bibliotecas. O mesmo pode ainda ocorrer em Instituições Sociais que cuidam de crianças e idosos...

De acordo com a realidade de origem dos estagiários, nos últimos tempos, propomos como atividade a organização de oficinas de produção de recursos didáticos, Projetos de organização de museus (ex.: Arroio do Tigre, Tupanciretã) e Projetos de ensino / pesquisa em: História das Missões, História Local e Regional, História e Cultura Afro-Indígena, Museologia e Ensino, História e Literatura do Rio Grande do Sul, planejados e dinamizados pelos acadêmicos e agregando alunos, professores e a comunidade.

Esse estágio é formado por três momentos: o primeiro é teórico quando são revisados os conceitos e temáticas a serem abordados; o segundo é a elaboração orientada do projeto; o terceiro é a aplicação prática - é o momento de intervenção na realidade local / regional. Como culminância, os estagiários organizam um seminário de vivências visando à socialização dos resultados para todos os alunos e professores do Curso de História. Essas inovações têm sido muito bem recebidas pelos alunos. Os resultados dessas experiências profícuas têm dado um novo sentido à prática. Outro aspecto a salientar é que tanto os Estágios Curriculares como as Práticas Docentes têm dado origem a artigos científicos e TCCs (Trabalhos de Conclusão de Curso).

\section{Considerações Finais}

As atividades relativas aos estágios supervisionados, redimensionadas pela LDB, são permeadas pela ação-reflexão-ação desenvolvidas em coletivo de sujeitos comprometidos com a dinamização de aprendizagens significativas. Essas relações reafirmam o papel da universidade a qual cabe no entendimento de Chaves Gamboa et al (2011, p. 143) a formação: 
Dos recursos humanos profissionais o compromisso com a construção teórica e as reflexões críticas em direção a formação humana atrelada ao desenvolvimento histórico da sociedade. Entretanto, tanto a teoria construída, como as reflexões críticas devem ter como parâmetro epistemológico a relação com a prática e serem orientadas pela "filosofia da práxis".

Os docentes do Curso de História responsáveis pelas orientações dos estágios assumem mutuamente com os professorandos compromissos e desafios que surgem ao longo do processo. Hoje os estágios têm sido vistos em uma nova perspectiva, onde de acordo com Jarmendia (2005, p. 112 - 113), se consolidam como:

\begin{abstract}
Um dos eixos curriculares que perpassa todo o currículo e favorece a integração das disciplinas e a articulação entre a teoria e prática; por meio dele é possível desencadear o processo de reflexão sobre a prática, bem como criar condições para retomar e revisar os conhecimentos teóricos e aprender com o saber de experiência do outro. O ES deixa de ser, exclusivamente horas a cumprir e passa a ser fonte de questões e situações problemáticas sobre a prática, que ser tornam objeto de discussão e reflexão no interior da sala de aula.
\end{abstract}

Cabe ainda destacar que os estágios integram as disciplinas de formação pedagógica, as quais, segundo Caimi (2008, p. 292) devem:

Oportunizar ao professorando (re)construções cognitivas no âmbito do pensar / saber e do saber / fazer e, de outra parte, que as práticas e os estágios, superando o caráter técnicoinstrumental que Ihes são tradicionalmente atribuídas, possam assumir a reflexão téorico-metodológica como instância cognitivo-explicativa do trabalho docente.

É inevitável não esquecer que um dia a sociedade nos entregou esses alunos e espera que a ela voltem adequadamente formados, competentes e capazes de responder às demandas dos tempos modernos. Acreditamos que os estágios desenvolvidos no Curso de História da Unicruz, desempenham um papel importante na formação e qualificação profissional, ao Ihe conferir um diploma, não podem pairar dúvidas que na somatória entre teoria e prática, este cidadão 
detenha os conhecimentos necessários ao bom desempenho de uma profissão. A sua realização em diferentes espaços sócio-educativos e culturais viabilizam, de forma qualificada, á práxis aproximando da mesma os conceitos de dialogicidade, ação-reflexão, autonomia e docência. Ao optarem pelo viés da interdisciplinaridade as experiências de estágio inovam e permitem o que Aires (2011, p. 218) destaca:

A interdisciplinaridade representa um instrumento de crítica interna do saber, buscando superar o isolamento das disciplinas, em relação aos outros domínios da atividade humana e nos diversos setores do próprio saber, como também uma modalidade inovadora que pode superar a distância entre a universidade e a sociedade.

Por tratarmos, neste texto, da formação de professor, dos estágios curriculares e do ensino de história consideramos significativo trazer para o mesmo uma passagem pertinente do estudo realizado por Moreira José (2008, p. 88) quando esta lembra Fazenda (2003, p. 61) ao dizer:

O ensino de história deve procurar cultivar valores, atitudes e hábitos que libertem o indivíduo do isolamento cultural ao qual a civilização acidental o condenou. Nesse sentido, a história, vista sob perspectiva interdisciplinar, deve ser mais que simples ordenação sequencial e manuseio de certos materiais para consulta, deve plantar a semente do futuro pesquisador e do cidadão que luta por seus direitos e deveres, enfim, por sua liberdade.

Isto nos permite dizer que além do profissional também estamos desenvolvendo um cidadão capaz não somente de trabalhar, mas de pensar, criar, enfrentar problemas e as questões que a sociedade e\ou a profissão lhe fizerem. Por isso, é preciso ter claro que além do profissional, as universidades devem formar o cidadão.

É preciso, portanto, garantir que o aluno ultrapasse o espaço da sala de aula e passe a conviver com a realidade. Não basta formar um grande teórico, com muitas ideias. Cabe ajudá-lo a aprender pensar. Essa, certamente é uma grande contribuição que o estágio poderá proporcionar aos alunos e futuros profissionais.

Se, por um lado, devido à sua complexidade, não conseguimos, neste texto abarcar todos os seus aspectos que o tema contém, verificamos que as 
vivências nos passam a certeza de que os estágios concedem licença à práxis. Há que se considerar que os mesmos constituem-se um uma oportunidade promissora e eficaz de formação de consciência histórica, humana, docente e da cidadania, bem como de construção da memória. Poderíamos dizer tomando emprestada uma passagem de Seffner (2010, p. 214) que a realização deste texto "proporcionou a manutenção do "gosto" por ler e escrever História. Finalmente, as constatações registradas encaminham novos embates. É mister destacar que é preciso pensar e agir.

\section{Referências}

ABDALLA, M. de F. B.. A relação teoria e prática no campo de estágio. Revista de Educação. n. 26. Campinas: PUC / Campinas, jan./jun. 2009. p. 53-52.

ABUD, K. M. et al (Org.). Ensino de História. Idéias em Ação. São Paulo: CENGAGE, 2010.

ANDRÉ, M. E. D. A. Ensinar a pesquisa: como e para quê. In: VEIGA, I. P. de A. (org.). Lições de didática. Campinas: Papirus, 2006. p. 123-134.

AIRES, J. A. Integração curricular e interdisciplinares: sinônimos? Educação e Realidade. Ensino de História. N. 1, v. 36, Porto Alegre: UFRGS, jan./abr., 2011.

ARRUDA, E. P. Na tessitura das tramas virtuais: entre histórias, tecnologias e aprendizagens. In: FONSECA, S. G.; GATTI JUNIOR, D. (org.). Perspectiva do ensino de história: ensino, cidadania e consciência histórica. Uberlândia: UFU / FAPEMIG, 2011. p. 131-153.

BASTOS, M. H. C.; QUADROS, C. História da formação docente no Brasil. In: QUADROS, C. (Org.). Histórias e memórias dos 50 anos de formação de professores do Centro Universitário Franciscano de Santa Maria. Santa Maria: Unifra, 2005. p. 34-55.

BEZERRA, H. G. Ensino de história: conteúdos e conceitos básicos. In: KARNAL, L. (Org.). História na Sala de Aula. Conceitos, Práticas e Propostas. São Paulo: Contexto, 2003, p. 37-48.

BITTENCOURT, C. M. F. Ensino de história: fundamentos e métodos. São Paulo: Cortez, 2004.

BRASIL. Conselho Nacional de Educação. Parecer CNE / CP9, de 8 de maio de 2001. Diretrizes Curriculares para a Formação de Professores da Educação Básica, em nível superior, curso de licenciatura, de graduação plena. DOU, Brasília, 18 / 1 / 2001. Seção 1, p. 31.

Conselho Nacional de Educação. Parecer CNE / CP28, de 02 de outubro de 2001. Dá nova redação ao Parecer CNE / CP 21/2001, que estabelece a 
duração e a carga horária dos cursos de licenciatura, de graduação plena, de formação de professores da educação básica em nível superior. DOU, Brasília, 18 / 01 / 2001, c. Seção 1, p. 31.

Conselho Nacional de Educação. Resolução CNE / CP 02, de 19 de fevereiro de 2002. Institui a duração e a carga horária dos cursos de licenciatura, de graduação plena, de formação de professores da Educação Básica e nível superior. DOU, Brasília, 4/03/2002b. Seção 1, p. 9.

Orientações Curriculares para o Ensino Médio. História. Ciências Humanas. v. 3. Brasília: MEC/Secretaria de Educação Básica, 2006.

CAIMI, F. E. Aprendendo a ser professor de História. Passo Fundo: UPF, 2008.

CERRI, L. F. Ensino de História e consciência histórica. Implicações didáticas de uma discussão contemporânea. Rio de Janeiro: RGV, 2011.

CLOTET, J. A nobre tarefa de bem educar. Zero Hora, Porto Alegre. 02/03/2011, p. 5.

Chaves-gamboA, M.; GAMBOA, S. S.; TAFfAREL, C. Prática de ensino: formação e emancipação. 3 ed., Macéio: EDUFAL, 2011.

CORSETTI, B.; CANAN, S. R. A formação docente na área de História: reflexões a partir da análise das diretrizes curriculares para a formação de professores da Educação Básica. In: BARROSO, V. L. M. et. al. (Org.). Ensino de história. Desafios contemporâneos. Porto Alegre: ANPUH-RS / EST / Esclamação, 2010, p. 41-55.

FAZENDA, I. Interdisciplinaridade: qual o sentido? São Paulo: Paulus, 2003.

FONSECA, S. G. Didática e prática de ensino de história. 2 ed., Campinas: Papirus, 2004.

A constituição de saberes pedagógicos na formação inicial do professor para o ensino de História na educação básica. In: MONTEIRO, A. M. ; GASPARELLO, A. G.; MAGALHÃES, M. de S. (Org.). Ensino de história: sujeitos, saberes e práticas. Rio de Janeiro: Maud/FAPERJ, 2007, p. 149-156.

Aprender a ensinar História em espaços intersticiais: reflexão sobre o papel formativo do "Perspectivas". In: FONSECA, S. G.; GATTI JUNIOR, D. (org.). Perspectivas do ensino de história: ensino, cidadania e consciência histórica. Uberlândia: UFU/FAPEMIG, 2011, p. 275-283.

; COUTO, R. C. de. A formação de professores de História no Brasil: Perspectivas desafiadoras do nosso tempo. In: ZAMBONI, E.; FONSECA, S. G. (Org.). Espaços de formação do professor de História. Campinas: Papirus, 2008, p. 101-130.

FREIRE, P. Pedagogia da autonomia. 17 ed., Rio de Janeiro: Paz e Terra, 2000. GONÇALVES, J. W. Visões dos estagiários da escola. XVII Jornada de Ensino de História e Educação. Ensino de História no Cone Sul: Patrimônio Cultural, Territórios e Fronteiras. Jaguarão: UNIPAMPA / ANPUH-RS, 22 A 24 /08/2011.

HELFER, N. E. A formação continuada de professores de História da Educação Básica: o curso de Atualização em História e Geografia da UNISC. In: BARROSO, 
V. L. M. et. al. (org.). Ensino de história. Desafios contemporâneos. Porto Alegre: ANPUH-RS / EST / Exclamação, 2010. p. 73-86.

JARMENDIA, A. M. Aprender na prática: elementos para uma concepção. Revista Unicsul. Sociedade contemporânea. Novas dimensões em diálogo. Ano 10. N. 12. São Paulo: Universidade Cruzeiro do Sul, Junho, 2005. p. 117-125.

JAPIASSU, H. Interdisciplinaridade e patologia do saber. Rio de Janeiro: Imago, 1976.

ISAIA, S. M. de A.; PIVETA, H. M. P. Aprender a ser professor: o desenvolver de um oficio. Educação, v. 31, n. 3. Porto Alegre: PUCRS, set/dez, 2008, p. 250257.

LAMBER, P; SCHOFIELD, P. História. Introdução ao ensino e a prática. Porto Alegre: Penso / Artmed, 2011.

LAUTIER, N. Os saberes históricos em situação escolar; circulação, transformação e adaptação. Educação e Realidade. Ensino de História. v. 36, n. 1, p. 39 - 58. Porto Alegre: UFRGS, jan/abr. 2011.

LAVE, J.; WENGER, E. Situated learning:legitimate peripheral participation. Cambridge, UK: Cambridge University Press, 1991.

LIMA, C. R. E. Caminhos da Aprendizagem da Docência: Os Dilemas Profissionais dos Professores Iniciantes. In: VEIGA, I. P. A.; D' AVILLA, C. (org.). Profissão docente: novos sentidos, novas perspectivas. Campinas: Papirus, 2008, p. 135150.

MARTINS, E. C. de R. Historicidade e Consciência Histórica. In: SCHMIDT, M. A.; BARCA, I.; MARTINS, E. de R. (org.) Jörn Rüsen e o ensino de história. Curitiba/Minho: UFPR/Universidade do Minho, 2010.

A exemplaridade da História: prática e vivência do ensino. In:

FONSECA, S. G.; GATTI JUNIOR, D. (org.). Perspectivas do ensino de história: ensino, cidadania e consciência histórica. Uberlândia; UFU/FAPEMIG, 2011 ,p. 83-92.

MEINERZ, C. B. Ensino de História: A relação pedagógica em nossas práticas. BARROSO, V. L. M. et. al. (org.). Ensino de história. Desafios contemporâneos. Porto Alegre: ANPUH-RS / EST / Exclamação, 2010. p. 203-212.

MOREIRA JOSÉ, M. A. Interdisciplinaridade: e a interdisciplinaridade brasileira. In: FAZENDA, I. (org.). O que é interdisciplinaridade. São Paulo: Cortez, 2008, p. 85-95.

NÓVOA, A. (coord ). Os professores e a sua formação. 2 ed. Lisboa, Portugal: Dom Quixote Ltda, 1995.

OLIVEIRA, A. E. Os valores, o processo educativo e a prática docente. Educativa. v. 9. N. 02. Goiânia: UCG, jul./dez. 2007. p. 305-313.

PEREIRA, N. M.; GRAEBIN, C. M. G. Abordagem temática no ensino de história In: BARROSO, V. L. M. et al (org.). Ensino de história. Desafios contemporâneos. Porto Alegre: ANPUH-RS / EST / Exclamação, 2010. p. 169-181.

PIMENTA, S. G.; LIMA, M. S. L. Estágio e docência. São Paulo: Cortez, 2004. 
PIMENTA, S. G.; (org.). Saberes pedagógicos e atividade docente. 2 ed., São Paulo: Cortez, 2000.

RODRIGUES, M, M. Estágio Supervisionado: Licença concedida a realização da Práxis. Caesura. Revista Crítica de Ciências Sociais e Humanas. Especial Geografia. Canoas: ULBRA, jan/jun, 2004, p. 65-76.

ROSA, R. T. D.; VEIT, M. H. D. Estágio Docente: análise de interações sociais em sala de aula. Educação e Realidade. Ensino de História. v. 36, n. 1. Porto Alegre: UFRGS, jan./abr. 2011, p. 295-316.

ROSSATO, R. Práxis. In: STRECK, D. R.; REDIN, E.; ZITKOSKI, J. J. (org.).

Dicionário Paulo Freire. Belo Horizonte: Autêntica, 2008.

SEFFNER, F. Saberes da docência, saberes da disciplina e muitos imprevistos: atravessamentos no território do ensino de história. In: BARROSO, V. L. M. et al (org.). Ensino de história. Desafios contemporâneos. Porto Alegre: ANPUH-RS / EST / Exclamação, 2010. p. 213-230.

SOARES, O. P. A atividade de ensino de História: processo de formação de professores e alunos. Araraquara: Junqueira e Marin editores, 2008.

SOARES, S. R.; RIBEIRO, M. L. As representações sociais sobre a Prática Educativa de professores de cursos de Licenciatura. In: VEIGA, I. P. A., D'AVILA, C. (org.). Profissão docente: novos sentidos, novas perspectivas. Campinas: Papirus, 2008, p. 89-106.

TARDIF, M. Saberes Docentes e formação profissional. Petrópolis: Vozes, 2002. LESSARD, C. O trabalho docente: elementos para uma teoria da docência como profissão de interações humanas. Petrópolis: Vozes, 2005. TRINDADE, D. F. Interdisciplinaridade: um novo olhar sobre as Ciências. In: FAZENDA, I. (org.). O que é interdisciplinaridade. São Paulo: Cortez, 2008, p. 65-83.

ZAMBONI, E.; MESQUITA, I. M. de. A Formação de professores de História no Brasil: perspectivas desafiadoras do nosso tempo. In: ZAMBONI, E.; FONSECA, S. G. (org.). Espaços de formação do professor de História. Campinas: Papirus, 2008, p. 131-162.

Recebido em 28 de novembro de 2012 Aprovado em 22 de fevereiro de 2013 